\title{
Giant left ventricular pseudoaneurysm following acute inferior wall myocardial infarction presenting with acute left ventricular failure: a rare complication
}

\author{
Soumya Patra, ${ }^{1}$ Sateeshchandra M Dhadake, ${ }^{1}$ Navin Agrawal, ${ }^{1}$ Manjunath $\mathrm{CN}^{2}$
}

${ }^{1}$ Department of Cardiology, Sri Jayadeva Institute of Cardiovascular Sciences \& Research, Bangalore, Karnataka, India ${ }^{2}$ Sri Jayadeva Institute of Cardiovascular Sciences \& Research, Bangalore, Karnataka, India

\section{Correspondence to} Dr Navin Agrawal, drnavinagrawal@gmail.com

\section{DESCRIPTION}

Left ventricular (LV) pseudoaneurysm is a rare but potentially lethal late mechanical complication of acute myocardial infarction (MI). ${ }^{1}$

We present a case of 50-year-old man who presented with acute inferior wall MI. He was treated with thrombolytic agent streptokinase. ECG showed ST elevation and T wave inversion in inferior leads (figure 1). Coronary angiogram on the next day showed significant stenosis in right coronary artery (figure 2 ; video 1 ). On the third day after MI, he developed a sudden onset of pulmonary oedema. Echocardiography showed rupture of posterolateral free wall of LV (figure 3; video 2). It also showed the formation of giant pseudoaneurysm with a diameter of $3 \mathrm{~cm} \times 7.1 \mathrm{~cm}$ (figure 4; video 3$)$.

Pseudoaneurysms are three times more often localised on the inferior and posterolateral wall, whereas true aneurysms in $80-90 \%$ of cases are located within the apical or on the anterolateral

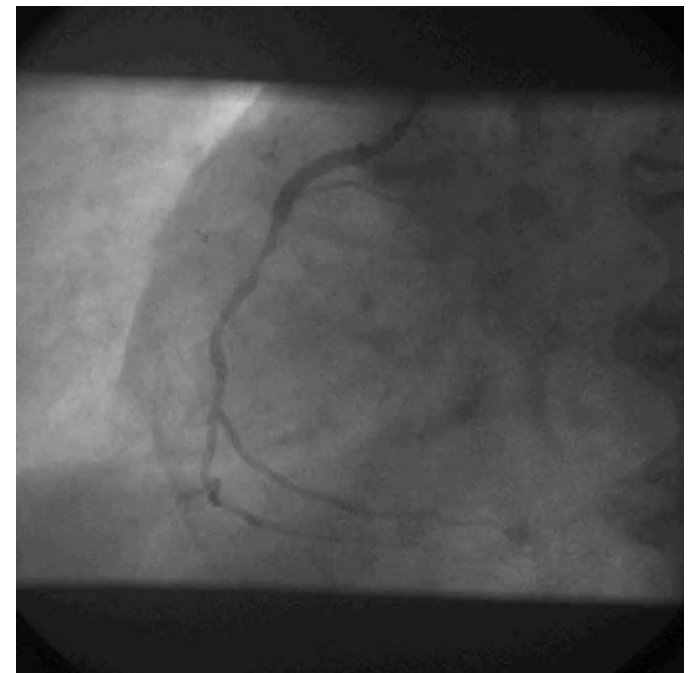

Figure 2 Coronary angiogram revealed significant stenosis in the right coronary artery.
To cite: Patra $S$,

Dhadake SM, Agrawal N, et al. BMJ Case Rep Published online: [please include Day Month Year] doi:10.1136/bcr-2013200270

Figure 1 ECG showing persistent ST elevation in inferior leads which is a marker of ventricular dyskinesia. 


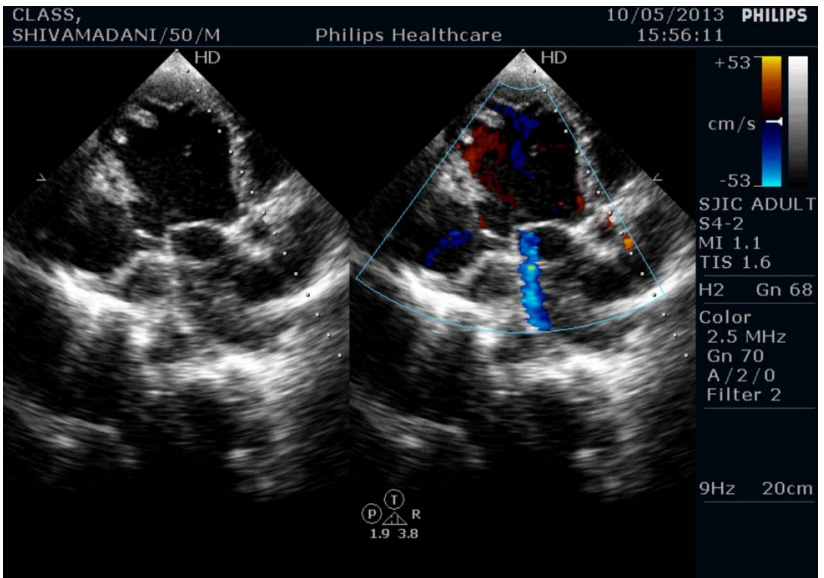

Video 1 Coronary angiogram revealed significant stenosis in RCA.

wall. Echocardiography shows a bounded echo-free space with the orifice of a narrow neck communicating with the $\mathrm{LV}^{2}$ with a ratio between aneurysm orifice dimension and its cavity diameter of $<0.5$, whereas a value of $>0.9$ suggests a true aneurysm of the LV. In Doppler echocardiography, there is a

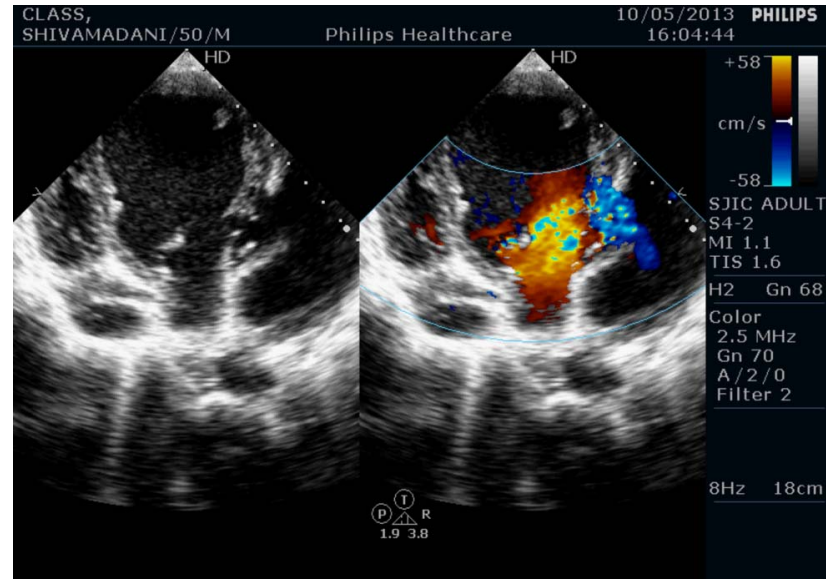

Video 2 Parasternal long axis view in echocardiography showed rupture of LV free wall with large pseudoaneurysm (PA). There was presence of moderate eccentric mitral regurgitation.

turbulent blood flow through the pseudoaneurysm orifice and laminar one in true aneurysms. Three-dimensional echocardiography with contrast offers enhanced endocardial border delineation of the LV, and better visualisation of the pseudoaneurysmal border.

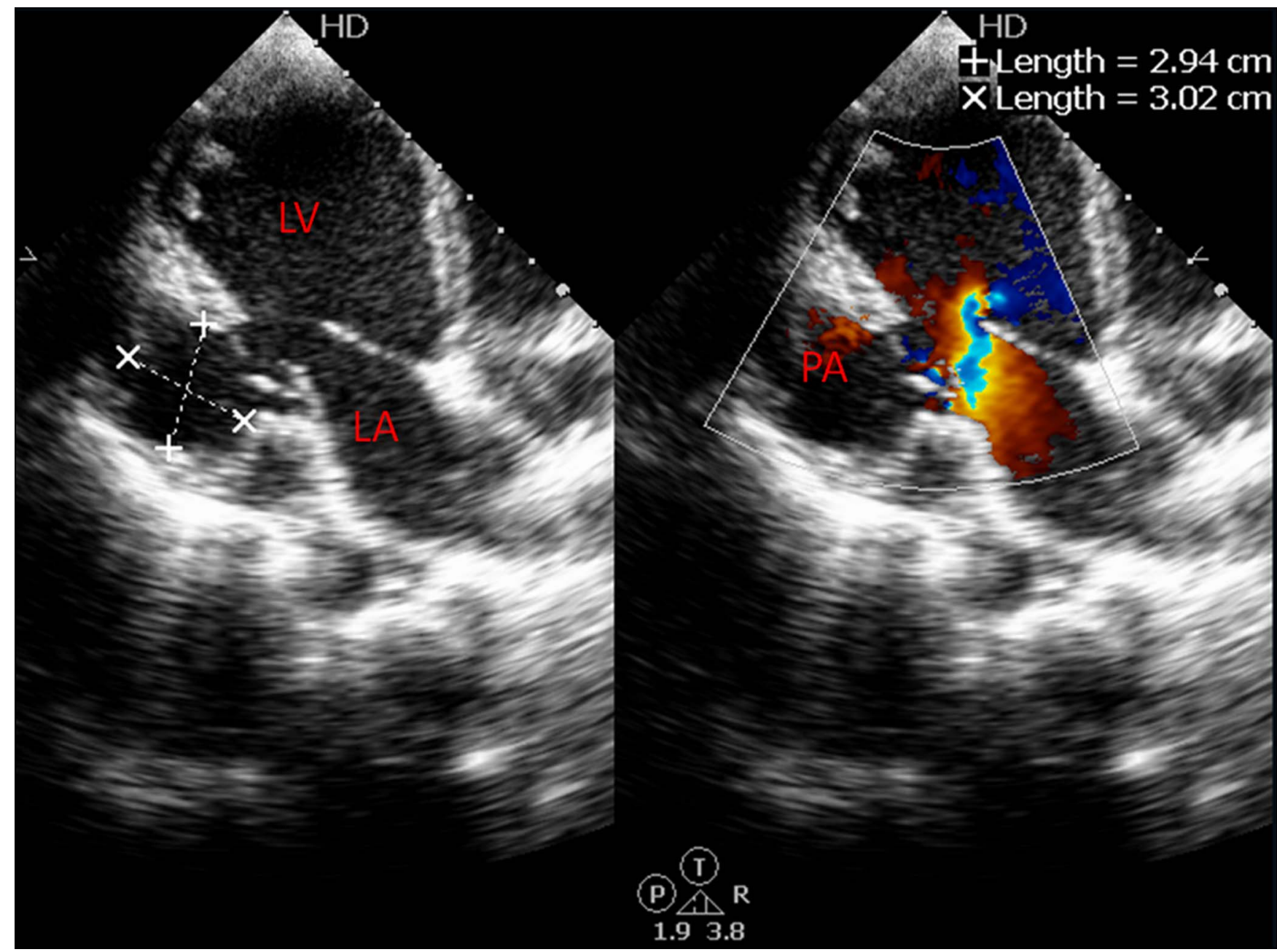

Figure 3 Parasternal long-axis view in echocardiography showing rupture of the left ventricular (LV) free wall with large pseudoaneurysm (PA). There was presence of moderate eccentric mitral regurgitation. 


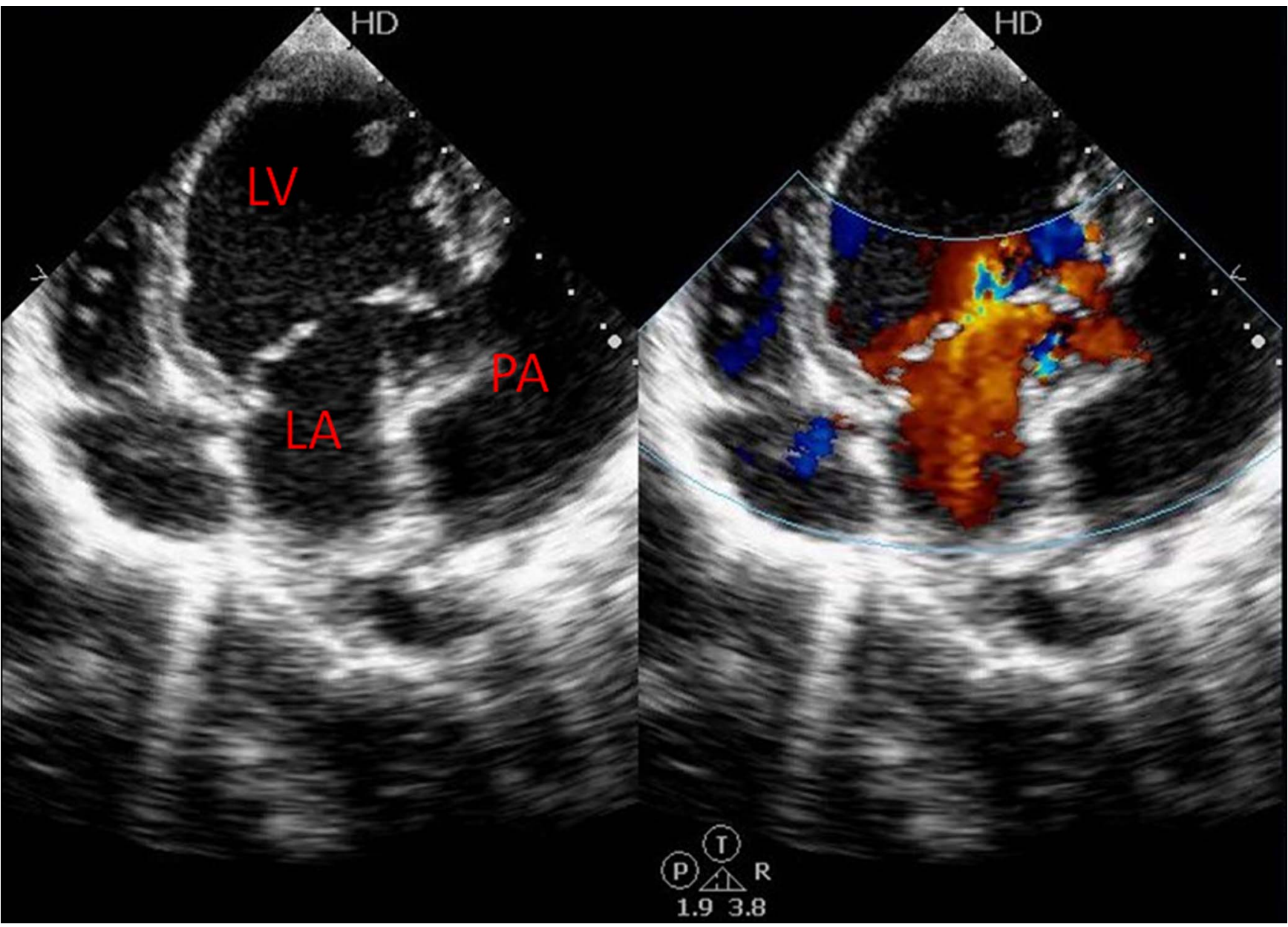

Figure 4 Apical 4C view showing rupture of lateral free wall of left ventricular (LV) with formation of pseudoaneurysm (PA).

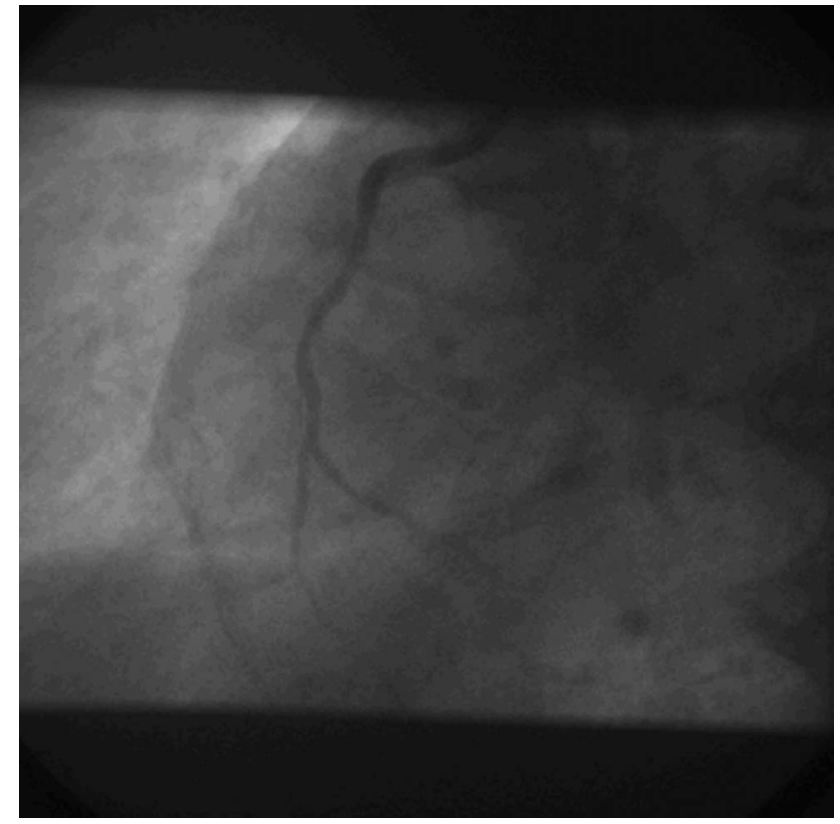

Video 3 Apical 4C view showed rupture of lateral free wall of left ventricular (LV) with formation of pseudoaneurysm.

The persistence of ST segment elevation above the baseline and the failure of the T wave to get inverted unlike the normal course of evolution of electrocardiographic changes after an MI for a long time is a relatively specific electrocardiographic marker of dyskinetic ventricle which also applies to aneurysm.

Thrombolysis in the management of uncomplicated MI has been shown to decrease the incidence of true aneurysm, but not that of pseudoaneurysm. In the case of pre-existing pseudoaneurysm, thrombolysis could dissolve the thrombus which was containing the leak, thereby causing pericardial tamponade and sudden cardiac arrest.

Pseudoaneurysms, unlike true aneurysm, have a propensity to spontaneous rupture; hence, immediate surgical intervention is the treatment of choice. ${ }^{3}$ If surgery cannot be done then vigilant follow-up and monitoring and control of blood pressure and LV remodelling with ACE inhibitors, $\beta$-blockers and spironolactone derivatives are required.

\section{Learning points}

- Left ventricular (LV) pseudoaneurysm is a rare but potentially lethal late mechanical complication of acute myocardial infarction (MI).

- Pseudoaneurysms have a propensity to spontaneous rupture; hence, immediate surgical intervention is the treatment of choice.

- In echocardiography, a ratio between aneurysm orifice dimension and its cavity diameter of $<0.5$ is highly indicative of pseudoaneurysm, whereas a value $>0.9$ suggests a true aneurysm of the LV. 


\section{Competing interests None.}

Patient consent Obtained.

Provenance and peer review Not commissioned; externally peer reviewed.
2 Dubey L, Timala R, Adhikari $\mathrm{R}$, et al. Unruptured left ventricular pseudoaneurysm following inferior wall myocardial infarction. Cardiol J 2012;19:539-42.

3 Erdim R, Yildirimturk 0 , Polat B, et al. Left ventricular pseudoaneurysm complicating inferior myocardial infarction: a case report. Int J Angiol 2011;20:107-10.

\section{REFERENCES}

1 Vijayvergiya R, Pattam J, Rana SS, et al. Giant left ventricular pseudoaneurysm presenting with hemoptysis. World J Cardiol 2012;4:218-20.

Copyright 2013 BMJ Publishing Group. All rights reserved. For permission to reuse any of this content visit http://group.bmj.com/group/rights-licensing/permissions.

BMJ Case Report Fellows may re-use this article for personal use and teaching without any further permission.

Become a Fellow of BMJ Case Reports today and you can:

- Submit as many cases as you like

- Enjoy fast sympathetic peer review and rapid publication of accepted articles

- Access all the published articles

- Re-use any of the published material for personal use and teaching without further permission

For information on Institutional Fellowships contact consortiasales@bmjgroup.com

Visit casereports.bmj.com for more articles like this and to become a Fellow 